\title{
Crohn's disease of the esophagus without inflammatory activity confirmed by the use of endoscopy with narrow-band imaging
}

Crohn's disease of the esophagus is uncommon. Better diagnostic tools, more frequent use of upper endoscopy, and careful histologic examination are probably the causes of the reported higher frequency of proximal Crohn's disease over the past decade [1-2].

We report the case of a 24-year-old female patient who presented to the emergency department with severe abdominal pain, bloody diarrhea, peripheral articular pain, and fever. She had no symptoms of esophageal disease (dysphagia or odynophagia). Upper gastrointestinal endoscopy revealed an extensive excavated lesion in the distal esophagus, measuring $4 \mathrm{~cm}$ in the longitudinal axis, covered by cicatricial tissue and with elevated margins. Some pseudodiverticula were also observed in the mid and distal esophagus but no evidence of inflammatory activity was macroscopically demonstrated ( $\bullet$ Fig. 1 a).

Narrow-band imaging also showed no increased vascularity ( $\bullet$ Fig. 1 b) [3-4]. Endoscopic ultrasound with a $12-\mathrm{MHz}$ probe showed hypoechoic and homogeneous thickening of the first to fourth layers of the esophageal wall in the site of the ulcerated lesion, without perilesional lymph nodes ( $\bullet$ Fig. 2) [5].

We repeated the upper gastrointestinal endoscopy at 6 and 12 months, and the endoscopic and histologic aspects remained the same.

We have to keep in mind all the differential diagnoses of esophageal ulcerated lesions in patients with Crohn's disease: infectious (cytomegalovirus, herpes simplex virus, typical and atypical mycobacteria, fungus) neoplastic, peptic, drugs (biphosphonates, ferrous sulfate, nonsteroidal anti-inflammatory drugs), and idiopathic ulcer related to the human immunodeficiency virus. Clinical history and histologic features can help us to differentiate these entities.

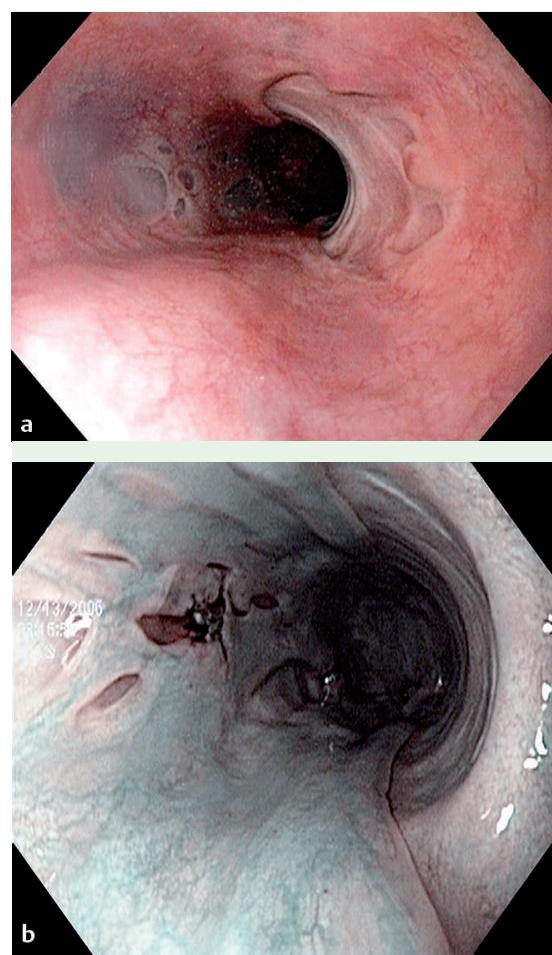

Fig. 1 Upper gastrointestinal endoscopy demonstrated an extensive excavated lesion in the distal esophagus, measuring $4 \mathrm{~cm}$ in the longitudinal axis, covered by cicatricial tissue and with elevated margins. Some pseudodiverticula in the mid and distal esophagus were also observed (a), with no evidence of inflammatory activity by narrow band imaging (b).

After establishing a probable diagnosis of Crohn's disease of the esophagus using endoscopic, histologic, and radiologic features, it can still be difficult to determine the activity of these lesions. The use of narrow band imaging can help us to distinguish between the active inflammatory process and cicatricial tissue in this setting.

Endoscopy_UCTN_Code_CCL_1AB_2AC_3AZ

\section{J. L. S. Souza, J. G. da Silva, A. M. Sipahi}

Diagnostic Center in Gastroenterology, Department of Gastroenterology, University of Sao Paulo, Sao Paulo, Brazil

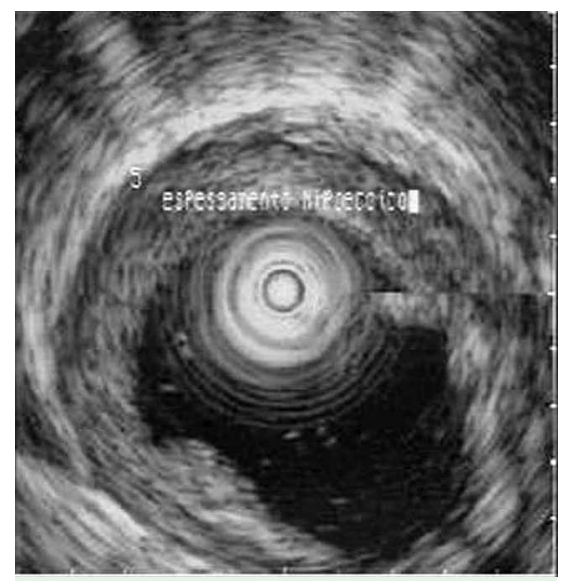

Fig. 2 Endoscopic ultrasound showed hypoechoic and homogeneous thickening of the first to fourth layers of the esophageal wall in the site of the ulcerated lesion.

\section{References}

1 van Hogezand RA, Witte AM, Veenendaal RA et al. Proximal Crohn's disease: review of the clinicopathologic features and therapy. Inflamm Bowel Dis 2001; 7: 328 - 337

2 Decker GA, Loftus EV Jr, Pasha TM et al. Crohn's disease of the esophagus: clinical features and outcomes. Inflamm Bowel Dis 2001; 7: 113-119

3 Kuznetsov K, Lambert R, Rey JF. Narrow-band imaging: potential and limitations. Endoscopy 2006; $38: 76-81$

4 Lee YC, Lin JT, Chiu HM et al. Intraobserver and interobserver consistency for grading esophagitis with narrow-band imaging. Gastrointest Endosc 2007; 66: 230-236

5 Lew RJ, Ginsberg GG. The role of endoscopic ultrasound in inflammatory bowel disease. Gastrointest Endosc Clin N Am 2002; 12: $561-571$

Bibliography

DOI 10.1055/s-0029-1214686

Endoscopy 2009; 41: E188

(c) Georg Thieme Verlag KG Stuttgart · New York . ISSN 0013-726X

Corresponding author

\section{J. L. S. Souza}

Diagnostic Center in Gastroenterology, Department of Gastroenterology,

University of Sao Paulo

255 Dr Enéas de Carvalho Aguiar Ave.

9th floor - Room 9159

São Paulo

Brazil

Fax: +55-11-30697940

jlsebba@gmail.com 